\title{
Sigmatic plurals in Romance varieties spoken in Italy and their interaction with $-i$ plurals
}

\author{
Leonardo M. Savoia, Benedetta Baldi, M. Rita Manzini \\ University of Florence, Italy
}

\begin{abstract}
In Sardinian, Friulian, Rhaeto-Romance, Occitan (not considered in this work) and Franco-Provençal varieties spoken in peripheral Italian areas, the $-i$ inflection is not totally eradicated but interacts with plural $-s$. The coexistence of $-s$ and $-i$ reflects syntactic constraints. Specifically, $-i$ is in complementary distribution with $-s$ or it combines with $-s$, giving rise to a duplicated lexicalization of plurality. In any event, it is specialized for a subset of the morpho-syntactic contexts. The distribution of $-i$ generally involves the $\mathrm{D}$ domain, i.e. determiners and clitics. In some cases, $-i$ is limited to the D elements. Different agreement systems on D and on $\mathrm{N}$ emerge, recalling partial or asymmetric agreement phenomena known in literature. Moreover, in the relevant varieties (-) $i$ is in turn the inflection of the dative clitic; this suggests that $(-) i$ is endowed with a slightly different content from plural $-s$, that, on the contrary, shows no connection with dative.
\end{abstract}

Keywords: morphology, plural, dative, agreement asymmetries, Romance variation

\section{Introduction}

In Italian and Romanian varieties plural- $i$ (and $-e$ ) contrast with plural $-s$ in West Romania (Meyer-Lübke 1899, Lausberg 1971, Sauzet 2012). In Sardinian, Friulian, Rhaeto-Romance, Occitan (that we will not consider in this work) and Franco-Provençal varieties spoken in peripheral Italian areas, the $-i$ inflection is not totally eradicated but interacts with $-s$. The compresence of $-i$ and $-s$ in these languages can be viewed as the reflex of the protracted competition and as the result of the old contact between the two types of number morphology.

The coexistence of $-s$ and $-i$, however, is not accidental, episodic or lexicalized, but is governed by a set of syntactic constraints. More precisely, $-i$ is specialized for a subset of morpho-syntactic contexts where it is in complementary distribution with $-s$ or it combines with $-s$ giving rise to a duplicated lexicalization of plurality. Specifically, the distribution of $-i$ generally involves the $\mathrm{D}$ domain, i.e. determiners and clitics. In some cases, $-i$ is limited to the D elements, configuring different agreement systems on $\mathrm{D}$ and on $\mathrm{N}$, and recalling the partial or asymmetric agreement systems known in the literature (Costa and Figueiredo 2002, Bonet 
et al. 2015). Moreover, in these varieties (-) $i$ is the inflection of the dative clitic; this suggests that $(-) i$ is endowed with a slightly different content from the plural $-s$, that, on the contrary, shows no connection with dative.

The data we discuss in this work $^{1}$ involve the connection between number, gender and agreement within DP and IP and raise the question on the nature of the inflectional elements inside N. Our model adopts the idea that morphosyntactic structures are projected from lexical items (Chomsky 1995, 2005). It assumes a morpheme-based analysis of inflectional phenomena and in general of the internal structure of the word, and that the same basic computational mechanisms underlie syntax and morphology (Manzini and Savoia 2005, 2011a,b, 2017a,b, forthcoming, Savoia et al. 2017a,b).

\section{Sardinian $-s$ systems}

In Sardinian systems $s^{2}$ the plural is expressed by the specialized $-s$ morpheme. In order to understand the examples, we note that in Sardinian varieties the ending /-s/ is subject to two types of allomorphic alternation. $-s$ in final position of sentence is generally followed by an epenthetic vowel copying the immediately preceding vowel, as in /feminas/ $\rightarrow$...feminaza, in (2a'). Moreover, in the internal contexts of sentence the final /-s/ undergoes lenition and assimilative changes depending on the initial consonant of the following word giving rise to an interesting micro-variation (Molinu 2013, Savoia 2015). So, when $-s$ precedes a voiced obstruent, it changes to -r e.g. in feminar bettsaza (<feminas bettsaza), in (1a') for Ardauli; in other dialects a palatal outcome occurs, for instance $-K$ in femina- $K v \varepsilon t t s-a-z a$ 'women old' in (3a) for Luras. In (2a') the sequence formed by the final $-s$ and the initial $f$-changes to $\int$, e.g. $i$ femminaza (< is femminaza), in (2a') for Orroli. Finally, in (3), -s assimilates to the following voiced sonorant e.g. in kussa llibbrozs?

Consider now the internal organization of the nominal inflection. $-s$ follows the nominal class vowel inflection. In Northern Sardinian, $-a$ - for the $1^{\text {st }}$ class, $-o-/-u$ for the $2^{\text {nd }}$ class and $-e-$ for the $3^{\text {rd }}$ class. We will concentrate on the $1^{\text {st }}$ and $2^{\text {nd }}$ class morphology. In the $2^{\text {nd }}$ class, $-u$ introduces the masculine singular and closes the noun; on the contrary, -o- occurs in-between the base and the plural $-s$ only signalizing the masculine class; besides, $-o$ closes the word in a small subset of nouns, like stt-o 'eight'. In the feminine $-a(-)$ occurs both as the singular inflection and the internal class inflection when followed by $-s$. So, we associate $-a(-)$ with the $\mathrm{f}($ eminine), $-u$ with $\mathrm{msg}$ (asculine singular) and $-o$ - with $\mathrm{m}$ (asculine). Finally, $-i$ characterizes the dative.

In (1a)-(1a') we illustrate the singular and plural forms for $1^{\text {st }}$ class nouns, where $-s$ follows the $-a$-inflection. In the masculines of the $2^{\text {nd }}$ class a split between the singular and plural vocalic inflection shows up, whereby $-u$ is the ending of the singular while in the plural the intermediate vocalic specialized inflection - $o$ - occurs, as evidenced by the comparison between (1b) for the

\footnotetext{
1 All the data examined in this article have been gathered through field work with native informants in the last few years. We sincerely thank them for their collaboration.

2 For a comprehensive view cf. Blasco Ferrer and Contini 1988, Jones 1993.
} 
singular and (1b') for the plural. In (1c), dative clitics, singular and plural, are exemplified, where the $-i$ inflection occurs.

(1) a. s-a/kuss-a vemin-a etts-a

the-f/this-f woman-f old-f

'the/this old woman'

a'. s-a-s/kus-a-s femin-a-r betts-a-za

the-f-pl /this-f-pl women-f-pl old-fsg-pl

'the/these old women'

b. kuss-u att-u etts-u

this-msg cat-msg old-msg

'this old cat'

b'. kuss-o-z att-o-r betts-o-zo

this-m-pl cat-m-pl old-m-pl

'these old cats'

c. $\mathrm{d}-\mathrm{i} \quad / \mathrm{d}-\mathrm{i}-\mathrm{r}$ dza-ða yust-u

him-her-dat / them-dat give-3sg this-msg

'he gives him/her/them this'

Ardauli

In Southern Sardinian dialects the feminines present the same inflection, as in $(2 \mathrm{a}, \mathrm{a})$. In the case of the masculines, the original mid post-tonic vowels have turned into high vowels owing to a neutralization process that has obscured the alternation between $-u$ as msg ending and the original internal inflection $-o$ - in the $2^{\text {nd }}$ class masculine nouns. This distribution characterizes also object clitics, in (2c). As a consequence, there is no longer a specialized vocalic inflection for the plural and $-u(-)$ occurs both in singular, in (2b) and in plural, as in (2b'). In Southern varieties the morpheme $-i$ lexicalizes the dative in clitics, as in $\left(2 c^{\prime}\right)$, and, moreover, it occurs in the plural determiners, indifferently in masculine and feminine contexts, as exemplified in $\left(2 a^{\prime}, b^{\prime}\right)$. For reasons of descriptive clearness we distinguish the plural reading pl from the dative one, except arrive to a common treatment in Section 5.

(2) a. s-a vemmin-a / s oriy-a

the-f woman-f / the ear-F

'the woman' 'the ear'

a'. i Semmin-a-za (< is femminaza) / i-z oriy-a-za

the-pl women-f-pl / the-pl-pl ear-f-pl

'the women' 'the ears'

b. s-u att-u (<su gattu)

the-m cat-m

'the cat'

b'. i yatt-u-zu (< is gattuzu)

the-pl cat-m-pl

'the cats'

c. $\mathrm{d}-\mathrm{u} / \mathrm{d}-\mathrm{a} / \mathrm{d}-\mathrm{u}-\mathrm{zu} / \mathrm{d}-\mathrm{a}-\mathrm{za}$ bbi-u

him-m/her-f/them-m-/-f-pl see-1ps

'I see him/her/them' 

c'. dd-i/dd-i-zi $\quad$ (d)ona-ða yust-u
him/her-dat/them-dat give-3sg this-m
'He gives him/ her/ them this'

Orroli

Summarizing, in Sardinian dialects the (-)i inflection has the following distribution:

- It lexicalizes the dative interpretation in clitics (cf. Italian $g l i)$, as in (1c) and in (2c').

- In Southern Sardinian dialects the definite determiner $i$-s combines the inflection $i$ - with $-s$ in the masculine and feminine plural, as in $\left(2 a^{\prime}, b^{\prime}\right)$.

Some Northern Sardinian varieties (cf. Sanna 1975) present a specialized distribution of the plural vowel morphemes, giving rise to a particular type of syncretism in the plural. In the Luras dialect, in (3), the syncretism involves determiners and adjectives, which in the plural select the internal inflection $-a$ - both in $1^{\text {st }}$ class feminine ( $\left.3 \mathrm{a}^{\prime}\right)$ and in the $2^{\text {nd }}$ class masculine ( $\left.3 b^{\prime}\right)$. In turn, object clitics (OCl) have only one form $l-a-s$ in the plural, as in (3c). Again $-i$ the dative inflection in object clitics, in (3c').

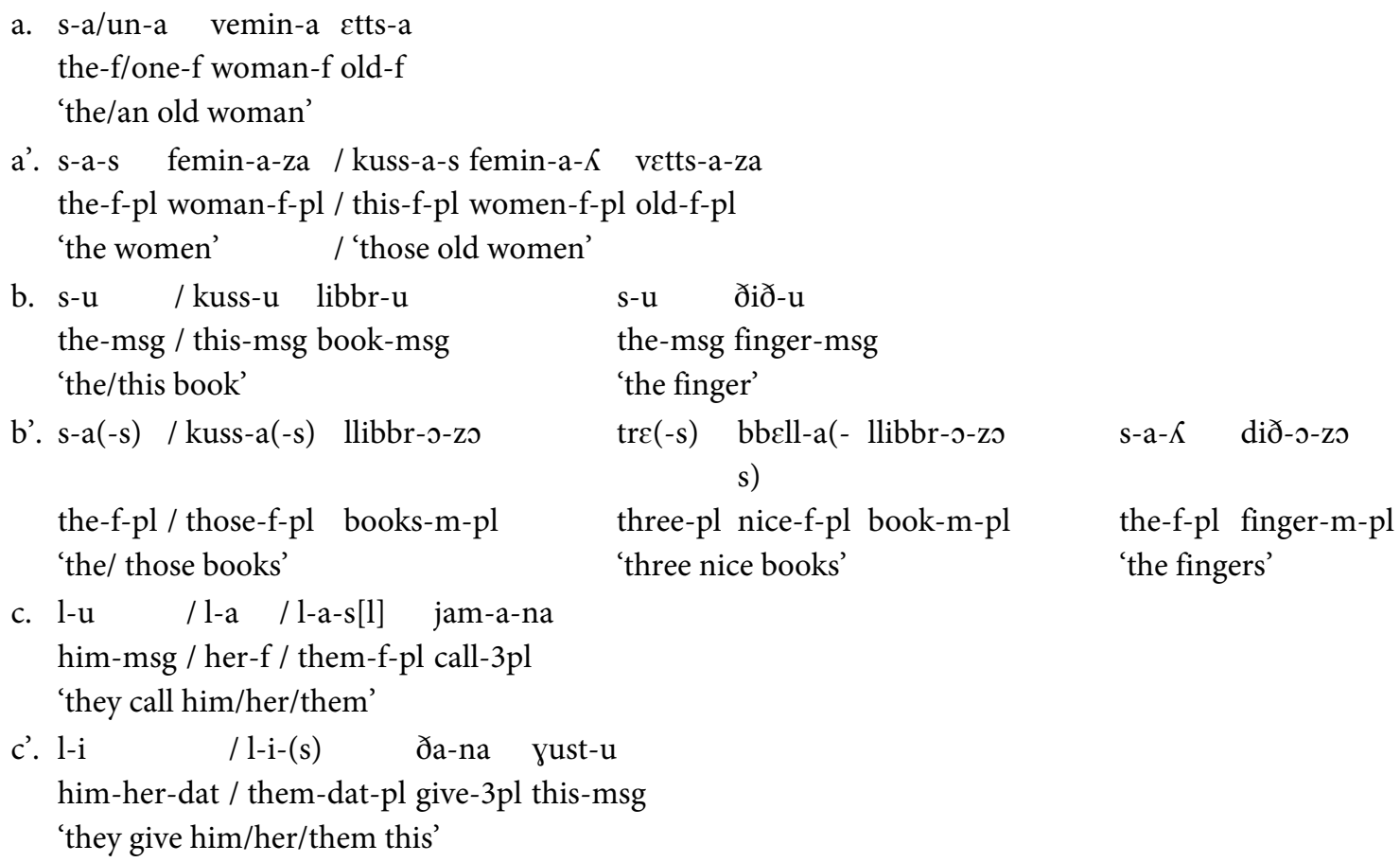

The label $\mathrm{f}$ for $-a$-in the examples in (3) has only a descriptive character. In fact, in this dialect it occurs both in feminine and in masculine agreement contexts, hence implying a deeper common property. 


\subsection{Rhaeto-Romance varieties}

\subsubsection{Friulian}

Microvariation in Friulian brings into focus the special nature of (-)i. In the data in (4a-b), from Comeglians (Central Friuli), (-) $i$ is in complementary distribution with the $-s$ plural morpheme. $-s$ occurs in the feminines in (4a') and in a subset of the masculines, in (4b'). In the masculine plural a threefold possibility is attested, i.e. $-i,-s$ or a palatalized outcome of the final obstruent - e.g. dinc 'teeth-, as in (4b'). $i$ occurs as the morpheme of the masculine plural in determiners, in (4b'), and in $\mathrm{OCl} i-u$, in (4c); in subject clitics (SCl), in (4c), plural (-)i occurs in the $1^{\text {st }} / 2^{\text {nd }}$ plural person and in the $3^{\text {rd }}$ plural person $a-i$, where it alternates with the form $a$. Finally, $-i$ - is associated with the dative clitic, as illustrated by the examples in (4d) concerning the singular dative; it is of note that plural dative has a specialized form $u r$ (< Latin illorum), as in (4d').

(4) a. l-a / ke femin-a vec-a

the-f / that woman-f old-f

'the/this old woman'

a'. 1-a-s / ke:-s (vec-a-s) femin-a-s (vec-a-s)

the-f-pl / those-pl (old-f-pl) women-f-pl (old-f-pl)

'the/those old women'

b. kel bjel jat / / dint that nice cat / the tooth

b'. ke-i / i jat-s / i dinc / i cave-i

those-pl / the.pl cat-pl / the.pl teeth.pl / the.pl hair-pl

'those/the cats / the teeth / the hair'

ke-i bje-i / vec-u-s jats

those-pl nice-pl / old-m-pl cat-pl

'those nice/old cats'

c. i durm-in / i durm-i:s / a(-i) duarm-int

SCl-pl sleep-1pl / SCl-pl sleep-2pl / SCl-pl sleep-3pl

c'. tu l-u /1-a /i-u /1-a-s iouk-s

you him-m / her-f / pl-m / her-f-pl see-2sg

'you see him/her/them'

d. a i da keft

$\mathrm{SCl}$ him/her-dat gives-3sg this

'He gives him/her this'

d'. a ur da keft

$\mathrm{SCl}$ them.pl give.3sg this

'He gives them this'

Comeglians

In other varieties of West Friuli, such as San Giorgio della Richinvelda, (-) $i$ is even more scattered in the paradigm, as illustrated in detail in (5). (-)i occurs as the inflection of the plural in the feminines, where it is followed by the $-s$ morpheme, as shown in (5a). In some sub-classes of feminines we find only $-s$. As regards masculines, two systems show up: $-s$ is inserted in many nouns with the base in consonant, as in (5b), $-i$ occurs in a subclass of nouns ending in lateral as in (5b'). The final $-i$ that characterizes a sub-set of singular masculines, as libr- $i$ 'book', vol- $i$ 
'eye', etc. would seem to originate form a syllabic requirement excluding final sequences obstruent-sonorant. ${ }^{3}$

(5) a. 1-a botf-a /1-a dzamb-a/1-a man the-f mouth- $f$ the-f leg-f the-f hand 'the mouth' 'the leg' 'the hand'

a'. 1-i bot $\int-\mathrm{i}-\mathrm{s} \quad / 1-\mathrm{i}$ dzamb-i-s / li man-s the-pl mouth-pl-pl the-pl leg-pl-pl the-pl hand-pl 'the mouths' 'the legs' 'the hands'

b. il ko:r / fouk/il dint / il dzal the.msg heart / fire / the.msg tooth the.msg cock 'the heart /fire / the tooth the cock'

b'. i ko:r-s / fouk-s/i $\operatorname{dint} \int / \mathrm{i} \quad$ dza-i the.pl heart-pl / fire-pl / the.pl teeth.pl / the-pl cock-pl 'the hearts / fires / the teeth the cocks'

If we look at the distribution of the plural inflections inside the DP, we see that the article is marked only by the $-i$ ending in the feminine (6a'). Demonstratives may in turn lack $-s$, as in (6a'). The simple $i$ plural inflection characterizes the masculine in the article and in the demonstratives, in (7a'), while other prenominal modifiers vary (altr-i-s vs. bje-i). Prenominal $1^{\text {st }} / 2^{\text {nd }} / 3^{\text {rd }}$ person possessives set the plural feminine apart from the plural masculine by associating the feminine with $-s$ and the masculine with $-i$, as in (6a') and (7a'). Finally (6a) and (7a) illustrate singular contexts and (6a") and (7a") illustrate the contexts with post-nominal adjectives.

(6) a. l-a / kist-a / ke bjel-a femin-a the-fsg / this-fsg / that fine-fsg woman-fsg

a'. l-i / kist-i(-s) / ke bjel-i-s femin-i-s the-pl / these-pl-pl / those fine-pl-pl women-pl-pl

a” $k \varepsilon$ femin-a grand-a that woman-fsg old-fsg

(7) a. il / kist-u / kel bjel tfan the / this-msg / that nice dog

il no $t$ fan

the my.msg dog 'my dog'

a'. i / kist-i / ke-i bje-i tfan-s the.pl / these-pl / those-pl nice-pl dog-pl 'the/these/those nice dogs'

a”. kel tfan gra:nt that dog big 'that big dog' 1-a me t famez-a

the-fsg my.fsg shirt-fsg

l-i me:-s tfamez-i-s

the-pl my.f-pl shirt-pl-pl

$k \varepsilon(-s) \quad$ femin-i-s grand-i-s those-pl women-pl-pl old-pl-pl

San Giorgio

\footnotetext{
3 The status of $-i$ in masculine singular lies outside the scope of this article; however, the point will be briefly picked up in Section 5.
} 
The participles, in $\left(8 \mathrm{a}, \mathrm{a}^{\prime}\right)$, for unaccusatives and transitives respectively, display the same inflectional system as nouns and adjectives, whereby feminine plural includes $-i$-s and masculine plural $-s$. In the paradigm of subject clitics, in (8b), $i$ is associated to the $1^{\text {st }}, 4^{\text {th }}$ and $5^{\text {th }}$ person. Object clitics, in (8a'), insert $i$ in the plural forms, distinguishing masculine plural $i-u$ from feminine plural $l-i$; however, the feminine plural form $l-i-s$ is selected in final position of imperatives, as in (8c'). Moreover, $-i$ characterizes also the dative clitic, which presents two alternants $i / g$ - $i$, which can combine, doubling the lexicalization of the possessor, as in (8c'). In $\left(8 c^{\prime}\right)$ we label the $-l$ morpheme generally occurring in definite determiners as Def.

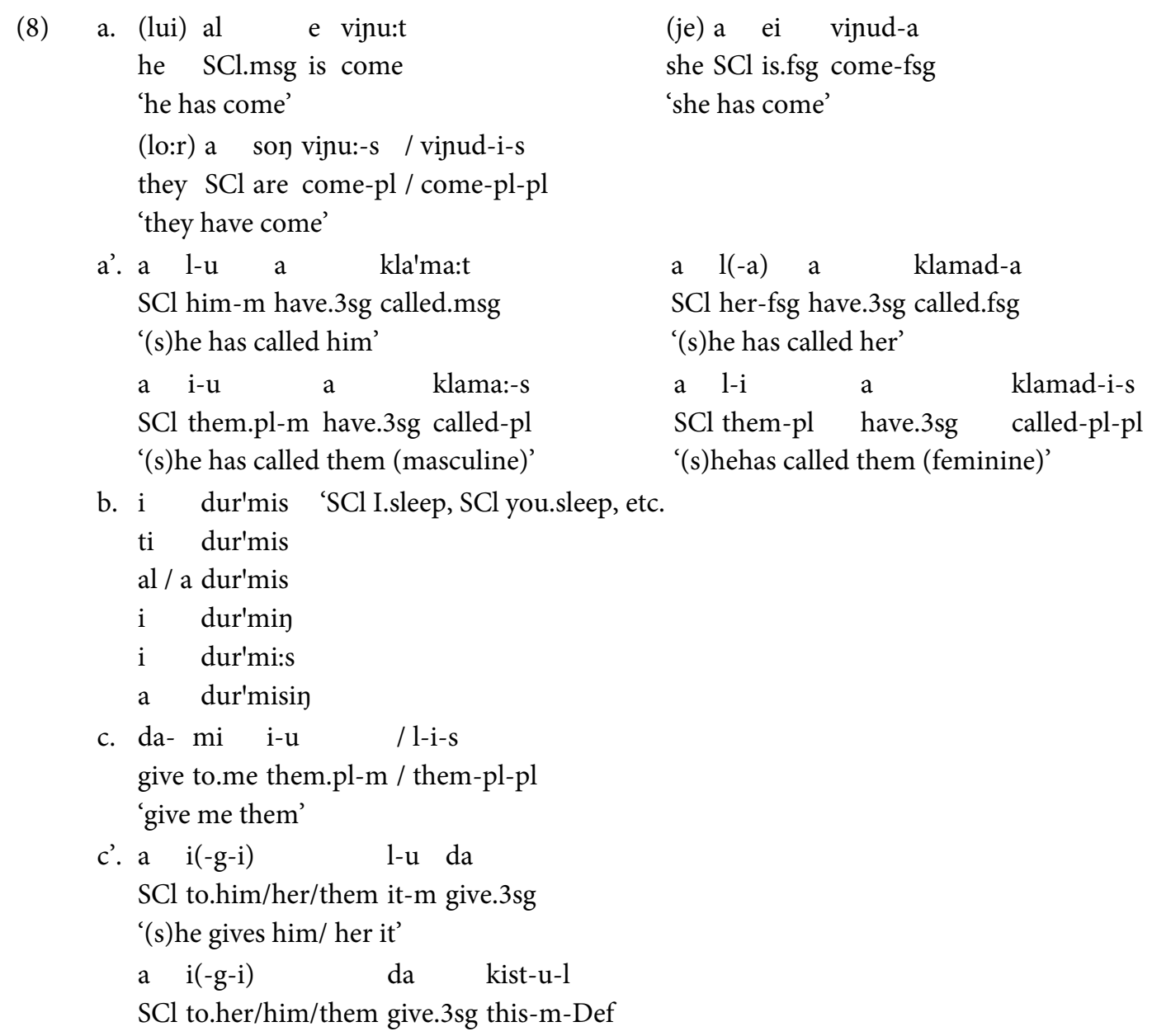

San Giorgio

\subsubsection{Ladin (Rhaeto-Romance of Val Badia)}

In Ladin varieties of $\mathrm{Val}$ Badia feminines and a subclass of masculines have the plural inflection $-s$, in (9a') and (9b'). Masculine determiners and a subset of the masculine nouns have (-)i, in (9b'). Plural masculine object clitics, in (9d), and dative, in (9d'), lexicalize as $i$. - $i$ characterizes the Subject clitic of $3^{\text {rd }}$ plural person, as in (9c). In the feminine plural in (9a) we tentatively identify the $-e$ - morpheme inserted between the base and the inflection as a Class exponent.

(9) a. 1-a dzam-a

the-fsg

'the leg' 


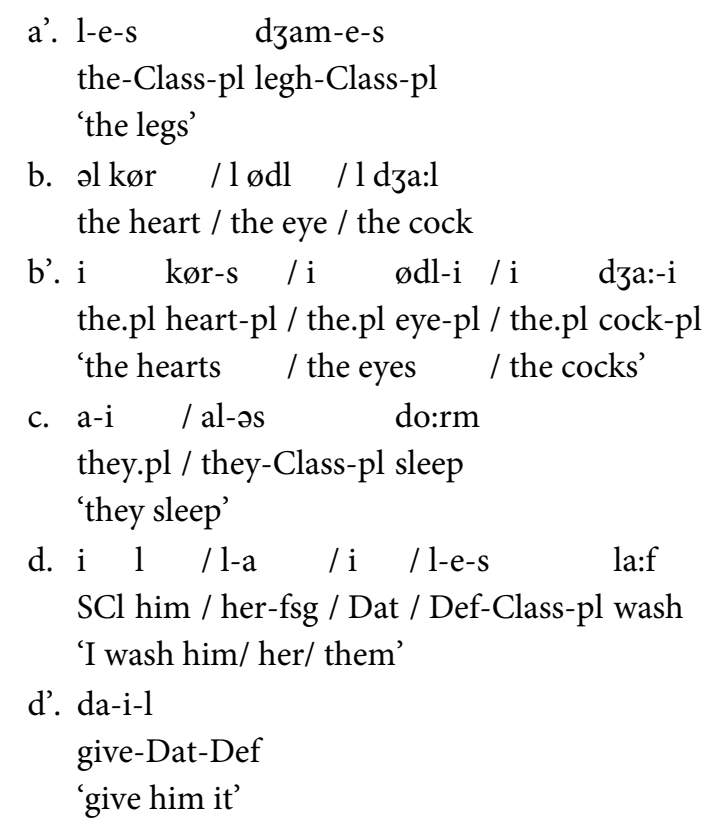

San Cassiano

\subsubsection{Romansh}

In Romansh varieties (Vattiz, Grisons), nouns, adjectives and determiners have the inflection $-s$ in masculine and feminine plurals, cf. (10a, a') and (10b,b'); in participles, $-s$ plural characterizes the feminine plural, in (10c), whereas the masculine plural has the $-i$ inflection, as in (10d). As in the preceding systems, we assign gender and number properties to the inflectional morphemes on the basis of their distribution. So, for instance, the occurrence of $-a(-)$ in singular and plural forms of feminines leads us to characterize it as $\mathrm{F}$ (eminine), independently of the number interpretation.

(10) a. l-a rod-a / /-a-s rod-a-s the-f wheele-f / the-f-pl wheele-f-pl

'the wheel/the wheels'

a'. kwel-a-s bun-a-s dun-a-s those- f-pl good- f-pl women-f-pl 'those good women'

b. iK kun'ti / i $\kappa$-s kuntial-s the knife / the-pl knife-pl 'the knife/the knives'

b'. kwel-s bun-s omən-s those-pl good-pl men-pl 'those good men'

c. El-a ai venid-a / \&l-a-s ai-n venid-a-s she-f is come-f / they-f-pl are come-f-pl 'she has come / they have come'

d. el ai veni-u-s / el-s ain veni-i he.m is come-f / they-pl are come- pl 'he has come / they have come' 


\subsection{Franco-Provençal}

In the system of plural inflection in Piedmontese Franco-Provençal varieties, here investigated through the data from Cantoira (Val Grande di Lanzo), $-s$ occurs in feminines, as in (11a'); masculine nouns lack any specialized morpheme for plural, as in (11b'). However (-)i characterizes masculine plural determiners and demonstratives, as in (11b'), the plural masculine $\mathrm{OCl}$, in (11c), and the dative argument in (11d). The inflection of feminine singular is $-a$ alternating with $-\partial$, as in (11a), whereas masculine plurals are devoid of inflection, in (11b).

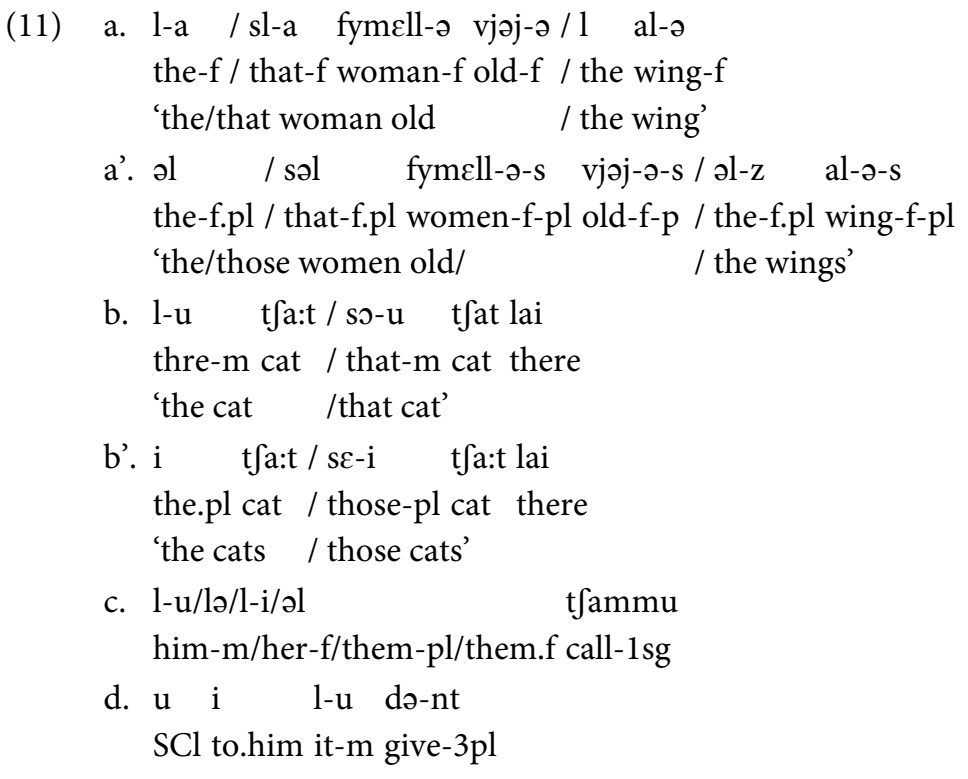

Cantoira

\subsection{Empirical generalizations}

On the whole, a type of micro-variation emerges in which the presence of $-s$ plural inflection does not exclude, but generally coexists with, the (-)i plural. (12) schematizes the distribution of the inflection (-) $i$ for plural and dative in the varieties we have so far examined. Specifically, (12) compares $-i$ and $-s$ in nouns, $\mathrm{N}-\mathrm{i}$ vs $\mathrm{N}-\mathrm{s}$, and registers the occurrence of $-i$ in the other contexts. In the dialects, where $-i$ or $-s$ characterize only masculine or feminine plural, the specification $\mathrm{m} / \mathrm{f}$ is introduced. All in all, we note that the specialized domain for $(-) i$ are the Determiners and Clitics. Determiners are dedicated places for the specialized plural inflection, so that we can find dialects in which the masculine plural nouns are devoid of a specialized morphologization of plural, as in Cantoira, while Determiners lexicalize it as - $i$. Object clitics systematically externalize masculine plural and dative by means of $-i$ inflection. The dialects endowed with subject clitics generally associate (-) $i$ to the masculine plural. Participles present the distribution holding in nouns and adjectives except in the case of Romansh varieties, where $-i$ inflection characterizes masculine plural only in participle. In (12) the subscript $\mathrm{m} / \mathrm{f}$ specify the gender interpretation of the (-)i inflection. 
(12) Plural (-)i

$\begin{array}{lcccccccc} & \mathrm{D}-\mathrm{i} & \mathrm{N}-\mathrm{i} & (\mathrm{N}-\mathrm{s}) & \text { Adj-i } & \mathrm{SCl} & \mathrm{OCl} & \mathrm{DatCl} & \text { Participle-i } \\ \text { Vattiz } & - & - & (+) & - & & & & +_{\mathrm{m}} \\ \text { Cantoira } & +_{\mathrm{m}} & - & \left(+_{\mathrm{f}}\right) & - & - & +_{\mathrm{m}} & + & - \\ \text { Comeglians } & +_{\mathrm{m}} & +_{\mathrm{m}} & (+) & +_{\mathrm{m}} & + & +_{\mathrm{m}} & + & - \\ \text { San Giorgio } & + & + & (+) & + & + & + & + & +_{\mathrm{f}} \\ \text { San Cassiano } & +_{\mathrm{m}} & +_{\mathrm{m}} & (+) & & +_{\mathrm{m}} & +_{\mathrm{m}} & + & - \\ \text { Ardauli } & - & - & (+) & - & & & + & \\ \text { Orroli } & + & - & (+) & - & & & + & \\ \text { Luras } & - & - & (+) & - & & & + & \end{array}$

Another factor of variation has to do with the selection of a specialized Class inflection morpheme in the context of $-s$, as illustrated in (13). In the Friulian variety of San Giorgio - $i$ extends both to feminine and masculine, where it combines with $-s$ marker, so generalizing the duplication of the plural inflection, as is the case in Sardinian for Orroli's $i-s$. It is of note that determiners separate the masculine plural, coinciding with the simple inflectional element $i$ (cf. (5)-(8)), and the feminine plural form, where - $i$ combines with the definiteness base $l$-. In North Sardinian Logudorese dialects, masculine plural selects a specialized Class Inflection vowel, i.e. -o-, as in Ardauli. As a consequence, the plural interpretation is doubled in two inflectional elements, $-s$ and $-o-$. In the dialect of Luras. $-a$ - lexicalizes plural, limitedly to determiners/demonstratives. In Cantoira's dialect in feminine plural the inflection - - - occurs

(13) Specialized Class Inflection in sigmatic plural

$\mathrm{N}$

$\mathrm{D}$

Vattiz

Cantoira $\quad+-\mathrm{e}-\mathrm{f}$

Comeglians

San Giorgio $\quad+-$ - -

S. Cassiano

Ardauli

Orroli

Luras

$\begin{array}{ll}+-\mathrm{O}_{\mathrm{m}} & \\ +-\mathrm{O}-\mathrm{m} & +-\mathrm{a}-\end{array}$

\section{Morphological analysis}

In what follows we will propose a model of the internal morphological organization of the noun based on the idea that inflectional elements are bona fide lexical entries endowed with interpretive content (Manzini and Savoia 2011b, 2017a,b, Savoia et al. 2017a,b). This theoretical assumption separates our approach to morphosyntax both from classical Distributed Morphology (DM) and from other models in which exponent are inserted under clusters of features subject to be manipulated by morphological rules. Specifically, as concerns the structure of the Noun, we assume that the first component is a root; following Marantz (1997), the root $\sqrt{ }$ is category-less. Next to the root a vocalic morpheme encodes properties that, depending on the language, include gender and/or number and/or declension class. A third slot may be available, specialized for number (e.g. Spanish) or for case (e.g. Latin). In the literature (Picallo 2008, cf. Déchaine et al. 2014 on Bantu nominal classes, Fassi Fehri 2015 on Arabic) at 
least two functional projections are needed in addition to the root - roughly gender and number.

In the approach we adopt, inflected nouns are analysed as the result of a Merge operation (Chomsky 2013) that combines a lexical root with Gender (feminine/masculine) and other classificatory properties including number, that contribute to specifying the argument introduced by the lexical root. Gender is selected by the root (cf. Acquaviva 2009, Kramer 2015) or freely combines with it determining a compositional interpretation. ${ }^{4}$ The category-less lexical root is interpreted as a predicate, in the terms of Higginbotham (1985) and merges with the inflectional/derivational elements (Gender, number and in general classifiers), which may be thought of as predicates that restrict the properties associated to the argument $x$ open at the predicate. In other words, these elements restrict the content of the argumental variable bound by Determiner/Quantifier.

The standard DM (Halle and Marantz 1993) treatment of inflectional class (Oltra-Massuet and Arregi 2005, Kramer 2015) has a Th(ematic vowel) node adjoined to Class $/ n$ postsyntactically. The content of Th are diacritics such as [I], [II], etc. for I, II inflectional class, etc. in turn spelled out as $-a,-o$, etc. (in Spanish, etc.). We do not adopt this treatment in so far as it presupposes post-syntactic Merge. We assign the inflectional morpheme to an Infl category, which syntactically merges with Class, including the root and its Gender specification. Class corresponds to Gender. The relation between inflectional elements, and Gender specifications can be understood in terms of selection by the inflection. Our various assumptions are schematized in (14).

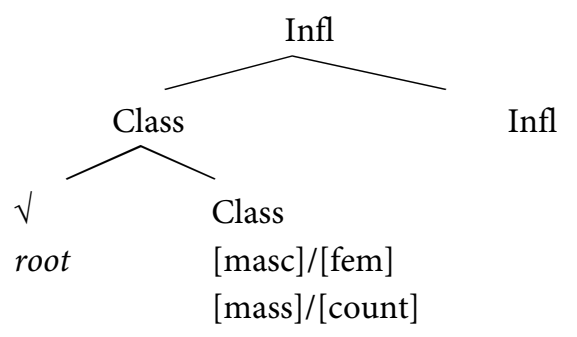

In Italian, the plural is obtained by a change of the inflection, differently from languages like Spanish and Sardinian, endowed with an independent lexicalization for the plural, namely $-s$. More precisely, we find alternations such as ragazz-o 'boy'/ragazz-i 'boys' in II class masculines, where the morpheme $-i$ is specialized for plurality. Otherwise, the plural is externalized by the -e inflections, cf. ragazz-a/ragazz-e 'girl/ girls', and - $a$, cf. dit-o/dit-a 'finger/ fingers', independently occurring as Gender specification in the singular.

In Sardinian varieties, where $-s$ of plural masculine combines with the specialized morphology $-o-$, contrasting with the $-u$ ending of the singular, Class elements $-a,-o,-u$ merge with the combination root-Gender, externalizing the inflectional class. The specialized morpheme $-s$ in turn introduces the plural, as in (15). Following the proposal in Manzini and Savoia $(2011 b, 2017 \mathrm{a}, \mathrm{b})$ plural morphology is associated to the part-whole/inclusion content,

4 In Romance languages, (root, Class) combinations interpreted compositionally are of the type gatt-o 'he-cat', gatt-a 'she-cat' in Italian. Some lass contents are determined directly by the root (see Italian donn- $a$ 'woman', feminine or marit-o 'husband', masculine). 
i.e. $[\subseteq]$. In other words, the content of the plural, $[\subseteq]$, suggests that the argument of the root can be partitioned into subsets. In (15), $[\subseteq$ s] merges with the set $\{\{$ femin- $[$ fem, $\subseteq]\} a\}$, independently lexicalizing the singular, giving rise to the plural femin-a-s, which unlike the atomic singular has the property of being divisible (into subsets).

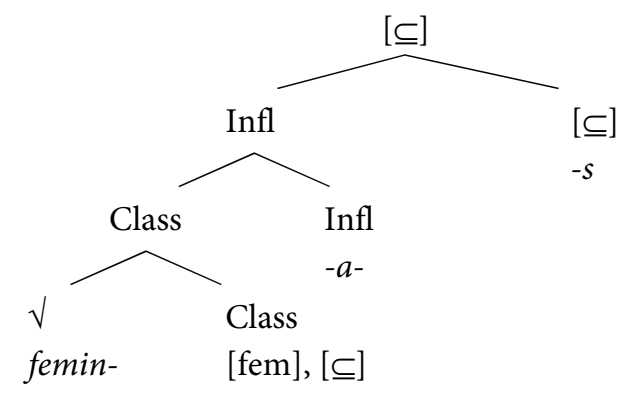

cf. (1a'), (2a'), (3a')

The $-a$ inflectional element in (15) or the $-u$ inflectional element attribute specifications such as sexed interpretations (and other) to the argument required by the root. In the case of the plural masculine of (b)att-o-s 'cats' in (16), a specialized inflectional exponent is selected, i.e. -o-, evidently associated to the plural. As a consequence, the plural is doubled on two different inflections, a vocalic morpheme, usually connected to Class/inflectional properties, and $-s$, specialized for $[\subseteq]$, as illustrated in (16). Tentatively we may conclude that $-a$ and $-u$ correspond to an individual interpretation in Sardinian, insofar as the plural is realized by $-s$. Since - $o$ emerges with $-s$, we may think that in the relevant varieties $-o$ - is specialized for the plural interpretation.

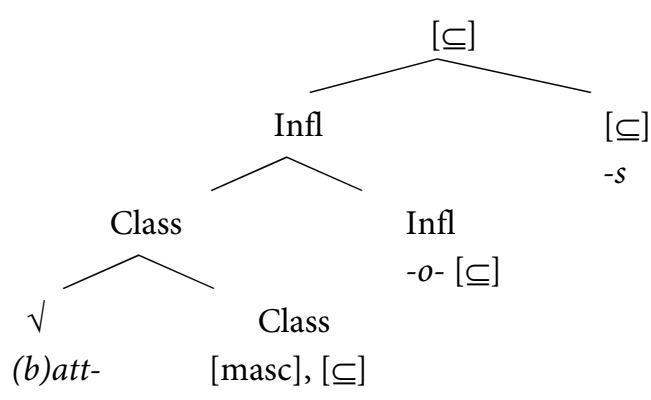

In Luras, the - $a$ - inflection is inserted in plural determiners/adjectives, independently of Gender and Class inflection of the noun. We are led to conclude that $-a$-is available for the plural reading. In other words, $-a$ - admits a plural interpretation. This recalls the fact that in many Romance varieties $-a$ introduces plurals in a subset of nouns, externalizing a collective interpretation, as in $(17 \mathrm{a}, \mathrm{b})$ for body parts in Standard Italian. In other dialects - $a$ occurs in the singular as well as in the plural of feminine nouns, as in some North Italian dialects, illustrated in (18a) with the North Lombardy variety of Tresivio (Valtellina), and in North West Tuscany dialects (Garfagnana and Lunigiana), as in (18b).
a. 1-a cas-a l-e cas-e
the-fsg house-fsg the-fpl house-fpl
a'. il dit-o l-e dit-a
the.msg finger-msg the-fpl finger- $\mathrm{f}(\mathrm{pl})$ 


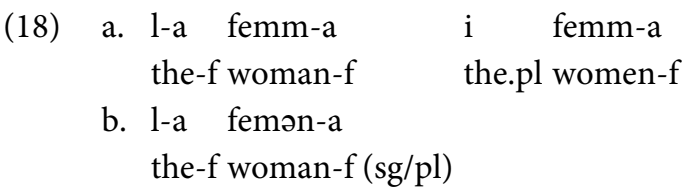

Manzini and Savoia (2017a,b) argue for an analysis that assigns the [aggregate] interpretive property to the $-a$ element, where [aggr] is understood as the conceptualization of a weakly differentiated set of individuals. The notion of aggregate is used by Chierchia (2010) to characterize the common core of mass and plural denotation. So, - $a$ plural, instantiating the content [aggr], can be kept distinct from the $-i$ plural. This raises the question how the [aggr] specification $-a$ on $\mathrm{N}$ comes to agree with the $[\subseteq]$ specifications that we have imputed to $-s$. One possibility is that [aggr], in that it introduces a type of plurality, is compatible with $[\subseteq]$; in effect the latter property is a subtype of the former. This analysis helps us treat the occurrence of - $a$ in the plural in $-s$ as endowed with the interpretation [aggr], doubling the plural interpretation introduced by $-s$. This can be seen in the feminine plural in (19a) and in the masculine plural D in $(19 b) .^{5}$

(19) a. [ [ [ [ femin] [Class fem] ] [ [nf [aggr] $-\mathrm{a}]][[\subseteq \subseteq]-s]$

b. [ [ [D s] [Class fem] ] [ [nf [aggr] -a] ] [[c] -s] dið-o-zo

In Southern Sardinian, the plural element $i$ - occurs in the definite article $i-s$. In these dialects, $-u$ is the inflectional vowel of masculine nouns both in singular and plural. Differently from -o-, it is not specialized for the plural interpretation. On the contrary, in the article, we again find a double realization of the plural, combining $-s$ with the $i$ - plural element, as in (20).

(20) $\quad\left[\left[\mathrm{i}_{\operatorname{Infl}[\subseteq]}\right] \mathrm{s}_{[\subseteq]}\right]$

cf. $\left(2 a^{\prime}, b^{\prime}\right)$

An interesting point is that the doubling in (20) somehow preserves the double plural specification $-o$-s in the Northern dialects in (16) by different morphological means.

\section{The interplay between $-s$ and $-i$}

In the Friulian, Ladin, Romansh and Franco-Provençal varieties in (5)-(11) we find a hybrid situation where the specialized $-s$ inflection and $-i$ coexist even while showing a partially different distribution. In Franco-Provençal (Cantoira), feminines preserve the $-s$ plural. (-) $i$ is restricted to the masculine plural of determiners, whereas masculine nouns lack inflection, as in (12). More precisely, masculine nouns lexicalize only the basic form both in the singular and in the plural like many North-Italian dialects (Rohlfs 1968 [1949], Manzini and Savoia 2005), as illustrated in (21). As a consequence, masculine nouns can be understood as including a class

\footnotetext{
Manzini and Savoia (op.cit,) discuss the further issue whether $-a$ is still [aggr] when appearing in the feminine singular. Needless to say one may stipulate that the [aggr] property is only optionally associated with $-a$. However, their proposal is that [aggr] is very much like [masc] or [fem]. Gender specifications are compositionally interpreted as referring to sex when taken together with animate roots - otherwise they will not be interpreted compositionally (they will be the equivalent of idioms). Similarly, [aggr] is compositionally interpreted with roots denoting mass referents or as plural.
} 
property, agreeing with that of the determiners and modifiers, which, on the contrary, lexicalize $[\subseteq]$ by means of the $-i$ inflection.

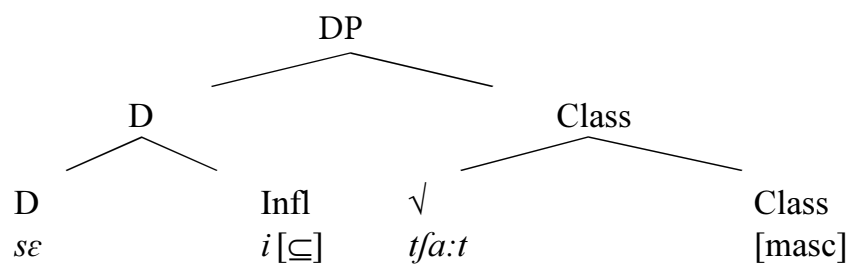

In Friulian (Comeglians, S. Giorgio) and Rhaeto-Romance (Vattiz, S. Cassiano), -s surfaces both in feminines and in masculines. The singular feminine has the inflection $-a$, the singular masculine is devoid of any specialized inflection. In Comeglians in (4) and in Vattiz in (10), where the feminine plural takes the form $-a-s,-a$ - complies with the plural interpretation, in the terms discussed in relation to (19).

In Surselva Romansh (Vattiz), $-i$ is confined to agreeing stative/unaccusative participles. In Friulian and Val Badia Ladin (S. Cassiano), $-i$ or palatalized forms occur in the plural of a subset of masculines. Palatalized plurals imply an original final $-i$, as in [dint $f$ ] 'teeth', [bjei] 'fine.mpl', from something like dint-i, bell-i, etc. Furthermore (-)i occurs in nominal determiners, modifiers and in clitics. In the masculine, $(-) i$ on the nouns and determiners is in complementary distribution with $-s$. In the San Giorgio variety, $-i$ - is required also in feminines, so that the plural is reduplicated in feminine nouns, as in (22a). In the feminine, then plurality systematically requires $-s$; in the masculine, $-i$ - is able to lexicalize plurality by itself. In short, in masculine plurals, only $-i$ or only $-s$ occurs, as in (22b) and (22c). In keeping with the analysis discussed above in (15), we associate $-s$ with the specialized plural element $[\subseteq]$. As to $-i$, it is associated with the same content, although a slightly different denotation seems to be evoked by its being able to introduce also the possessor, as seen in ( $\left.8 \mathrm{c}, \mathrm{c}^{\prime}\right)$. We return to this issue at the end of section 5 .

(22) a.

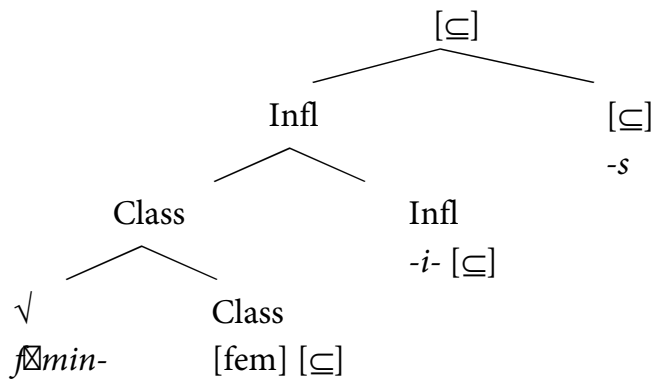

cf. (6a')

b.

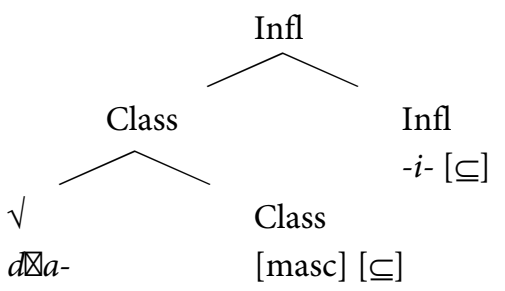

cf. (5b') 
c.

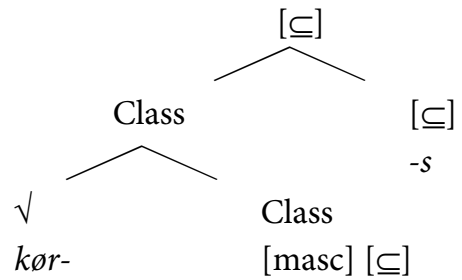

The data highlight a general trend whereby feminine is basically endowed with richer denotational morphology than masculine, which, on the contrary, favours a more parsimonious gender and plural morphology. This holds for Friulian and in a general perspective (RhaetoRomance, Franco-Provençal), as summarized in (23).

$\begin{array}{lcccc} & \text { feminine } & \text { masculine } & \text { feminine } & \text { masculine } \\ \text { Comeglians } & 1-\mathrm{a}-\mathrm{s} & \mathrm{i} & 1-\mathrm{a}-\mathrm{s} & \mathrm{i}-\mathrm{u} \\ \text { San Giorgio } & 1-\mathrm{i} & \mathrm{i} & 1-\mathrm{i}(-\mathrm{s}) & \mathrm{i}-\mathrm{u} \\ \text { San Cassiano } & 1-\mathrm{e}-\mathrm{s} & \mathrm{i} & 1-\mathrm{e}-\mathrm{s} & \mathrm{i} \\ \text { Cantoira } & \text { ol-s } & \mathrm{i} & \text { əl-s } & (1-) \mathrm{i}\end{array}$

In the feminine, exponents with stronger referential import are generally preserved. Thus, in feminines, $-a$, which has a clear referential interpretation (sexed/ aggregate), systematically occurs. In the plural, feminines enhance this interpretive content by requiring a regular externalization of plurality by means of $-s$ or possibly, of $-i$. Moreover, in many varieties, feminine articles and clitics require the $l$ - lexical base, associated with definiteness, whereas this is not necessarily the case for masculines.

\section{Asymmetries in plural specification and other restrictions}

A property shared by the varieties reviewed here is that all or part of the plural specifications are realized on the determiners and possibly in prenominal modifiers but not necessarily on nouns. In the literature, the asymmetry between the agreement properties of determiners (and nominal modifiers/adjectives) vs nouns have been brought to light (cf. Cinque 2009). Indeed, different types of split emerge. By way of an example, Bonet et al. (2015) discuss cases in which prenominal determiners and adjectives lack (a set of) agreement properties. Their idea is that prenominal agreement is due to a "family of constraints" enforcing general agreement at PF; on the contrary, postnominal agreement is syntactic in nature and triggered by Spec-Head agreement.

The hypothesis that different manifestations of agreement could be referred to different syntactic operations is pursued by several authors. Specifically, some approaches treat nounmodifier agreement (concord) as a process applying in the morphological component, separating it from the syntactic subject-verb agreement mechanism (Baier 2015). Nevins (2011: $8,9)$ deals with the different behaviour of plural and gender agreement in DPs in several languages by assuming that the ability of number in ambiguously extending to object or subject descends from the underspecified treatment of singular, whereby "unmarked values of number, e.g. [-singular], are never syntactically active and never referred to in the syntax". By contrast, 
"person features are always fully specified on syntactic arguments", thus excluding generalization processes. A mechanism based on the split between different types of features, namely marked vs. unmarked, is pursued in Pomino (2012) in accounting for the lack of number inflection in some Italian dialects.

Costa and Figueiredo (2002) present data concerning some Brazilian Portuguese varieties in which the plural inflection -s only occurs on the determiners o prenominal adjectives, as in O-s/est-es/algun-s/un-s livr-o muit-o bonit-o 'the/these/some book very nice'. Costa and Figueiredo adopt a distinction between dissociated and singleton morphemes. According to Embick and Noyer (2001), agreement and case morphemes are not syntactic projections and so they are not represented in syntax but they are added postsyntactically in morphology. Thus, dissociated morphemes convey an information "separated from the original locus of that information in the phrase marker" (Embick and Noyer 2001: 557). According to Costa and Figueiredo (2002), in European Portuguese, where plural agreement occurs on all elements inside DP, plural is a dissociate morpheme. The plural in Brazilian Portuguese corresponds to a specialized interpretable morpheme (singleton), which combines only with the "element anchoring the information concerning number", namely Determiners. Therefore, the Spechead configuration, responsible for Subject-I agreement, is different from the D-N relation, where the plural singleton occurs. ${ }^{6}$

Our data call into question these approaches in that the asymmetries between determiners/ prenominal modifiers and nouns involve not so much the realization of plural inflection as the nature of the plural inflection. As we have proposed, the element (-)i can be understood as a specialized morpheme, associated to determiners, subject or object clitics and possibly prenominal modifiers. In present terms, the fact that (-)i systematically lexicalizes the plural independently of gender distinctions means that its only content is the plural property $[\subseteq]$. If we concentrate on the Friulian variety of San Giorgio in (5)-(9), we see that - $i$ is able to lexicalize plural in any context, thus both on the determiner and the noun in (24) - though by itself only in determiners, $l-i$ for feminines like (24) and $i$ for masculines. Moreover, it is able to lexicalize plural in clitic occurrences, as exemplified in (8).

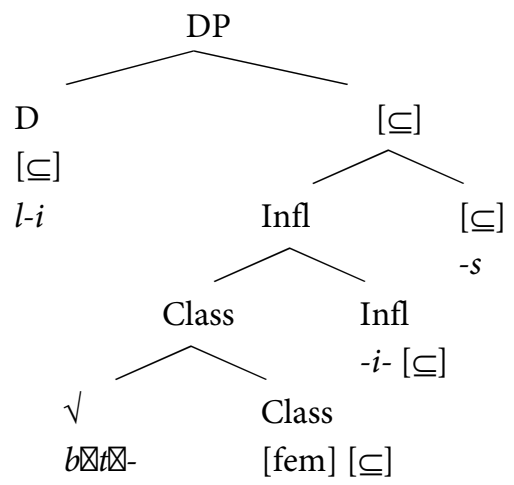

cf. (5a')

\footnotetext{
6 Following Vikner (1997), the presence of a specialized inflection in a sub-set of forms allows us to assume that the usual verbal agreement mechanisms apply. On this basis, Costa and Figueiredo conclude that despite the partial lack of Verb agreement in Brazilian Portuguese, it requires V-to-I movement and agreement just like European Portuguese.
} 
In the minimalist framework (Chomsky 2001), agreement processes are associated with the rule of Agree - conceived for agreement in the sentential domain. We keep the assumption that Agree also applies within DPs. However, what impels Agree to apply is the necessity of creating equivalence classes of phi-feature bundles denoting a single referent (Manzini and Savoia 2007, 2011a,b, 2017a,b, Savoia et al. 2017). In this way, we avoid introducing the interpretable/uninterpretable distinction (or the valued/unvalued one), which are particularly difficult to implement within the DP, where both the lexical head N and its Determiners can stake good claims to interpretable/intrinsically valued status.

Our approach is based on a privative treatment of the morphological properties in lexical elements. As stated at the outset, it excludes postsyntactic manipulation or insertion of new material, keeping instead to the hypothesis that syntax is projected from morphological terminals which have interpretive lexical content. As a result, the distinction between morphological agreement (dissociated) and syntactic agreement has to be rephrased as the split between agreement inflections with general occurrence and those with restricted distribution. As already mentioned, the distribution of $-s$ and (-) $i$ occurring complementarily or in combination, excludes the notion of dissociated morpheme as a morpheme generalized by externalization. Thus, in systems like those of San Cassiano in (8), San Giorgio in (7) and Comeglians in (4), where $-s$ occurs also in the masculine, the plural masculine determiners have the $-i$ inflection, co-occurring however with the ending $-s$ in the noun, as in $i k ø r s$ 'the hearts' (San Giorgio).

In other words, we witness a type of morpho-syntactic split, whereby definiteness and deictic elements are endowed with specialized morphology, imputable to the role they play in the identification of arguments. In general, the occurrence of specialized plural elements is associated with the head of DP phase, i.e. determiners D and possibly other nominal modifiers, as schematized in (25a). In the vP phase, schematized in (25b), object clitics generally lexicalize plural specifications by means of the specialized exponent (-)i. This fits in with the idea that object clitics are the true agreement head of the vP phase (Roberts 2010, Manzini et al. forthcoming). The selection of $-i$ in Romansh participles in (10) can be in turn explained as an instantiation of Object-v agreement, in varieties lacking object clitics, as in the case of Surselva Romansh. Finally, subject clitics in many varieties do not register a specialized plural reading. It is natural to relate this to the presence of a pronominal inflection on the finite verb in I heading the CP-phase in $(25 \mathrm{c})^{7}$.

(25) Friulian / Ladin / Romansh varieties: masculine plural

\begin{tabular}{|c|c|c|c|}
\hline \multirow[t]{2}{*}{ a. DP phase: } & $\mathrm{D}(\mathrm{Q})$ & Adj & $\mathrm{N}$ \\
\hline & $-\mathrm{i}$ & $-s /-i$ & $-s /-i$ \\
\hline \multirow[t]{2}{*}{ b. vP phase: } & $\mathrm{ObjCl}$ & \multicolumn{2}{|c|}{ v (Participle) } \\
\hline & $(-) \mathrm{i}$ & \multicolumn{2}{|c|}{-s/Ø/-i(Romansh) } \\
\hline \multirow[t]{2}{*}{ c. CP phase: } & SubjCl & \multicolumn{2}{|l|}{ I } \\
\hline & $\varnothing /(-) \mathrm{i}$ & \multicolumn{2}{|c|}{ verbal Infl } \\
\hline
\end{tabular}

Manzini et al. forthcoming propose to connect the distribution of the plural inflections with a parameter whereby an agreement property can be differently externalized on the head of the phase vs the complement of the phase. 
A question we have left out so far is the doubling of the plural by $-i$ - and $-s$. This suggests that in Romance $-s$ and $-i$ have a slightly different content. This conclusion is upheld by the fact that $-i$ is also the dative, so introducing an interpretation $[\subseteq]$ including also the possessive relation between possessor and possessed. Manzini and Savoia (2011a,b) connect dative to the inclusion, expressed by $[\subseteq]$, in which the dative is the locator or the possessor of the internal argument of the verb. In other words, the Romance dative (-)i inflection is able to take scope both over the nominal root, giving rise to the plural interpretation, and over the indirect object - internal argument pair, giving rise to the dative reading. On the contrary, $-s$ introduces the part-whole relation only on the nominal root (the plural); in this sense it. contrasts with the less specialized interpretation of $-i$, that in fact extends to the possessive inclusion reading. We see that in the instances of doubling, it is the more specialized, hence richer, content of $-s$ that takes scope over the less specialized, hence simpler $-i$ (cf. (19a)). Finally, the quantificational properties of $-i$ are compatible with singular in a subset of masculine nouns in Friulian (cf. San Giorgio in (5)), cf. fn. 3 .

\section{Conclusions}

This work deals with the question of the theoretical status of nominal inflections, specifically plural inflections, in some Romance varieties. Our intent is to better understand the interface between the computational system and externalization, the traditional syntax/morphology interface. The microvariation in the plural inflection that we have examined brings into light the interplay between $-i$ and $-s$ as plural exponents. Some general points arise as regards the distribution of $-i$ :

- $\quad$ (-)i plural typically appears on determiners and modifiers of the noun and in a subset of plural masculine nouns.

- $\quad(-) i$ plural is lexicalized in subject and object clitics

- $\quad(-) i$ lexicalizes dative

- $\quad(-) i$ may be associate also to feminine nouns (San Giorgio)

- $\quad(-) i$ can combine with $-s$ giving rise to doubling of plural morphology: this suggests a difference in the content of the two inflections.

We have connected these facts with the different nature of $-i$ and $-s$ in the light of a theoretical model where inflectional morphemes are endowed with interpretable content, on the basis of which syntactic structures and computations are built. In this perspective, agreement is the result of the equivalence between phi-feature bundles denoting a single referent. Our approach allowed us to account for the distribution of $-i$ by tying it to the requirements of the determiners and in general the modifiers of nouns. More precisely, we have connected $-i$ with the definiteness and deictic elements corresponding to the identification of arguments and playing the role of agreement head of phase. The association of $-i$ with dative suggests a partially different content from $-s$, so explaining their doubling 


\section{References}

Acquaviva, Paolo. 2009. "Roots and Lexicality in Distributed Morphology". In York Working Papers - Special Issue York-Essex Morphology Meeting May 2009, edited by Alexandra Galani, Daniel Redinger and Norman Yeo, $1-21$.

Baier, Nico. 2015. “Adjective Agreement in Noon: Evidence for a Split Theory of Noun-Modifier Concord”, Paper presented at LSA 2015, Portland.

Béjar, Susana and Milan Rezac. 2009. "Cyclic Agree”. Linguistic Inquiry 40: 35-73.

Blasco Ferrer, Eduardo and Michel Contini. 1988. "Sardisch: Interne Sprachgeschichte I. Grammatik”. In Lexikon der Romanistischen Linguistik. IV: Italienisch, Korsisch, Sardisch. edited by Günter Holtus, Michael Metzeltin and Christian Schmitt, 836-853. Tübingen: De Gruyter.

Blevins, James. 2006. "Word-based morphology". Journal of Linguistics 42. 531-573.

Bonet, Eulàlia and Joan Mascaró, 2012. "Asimetrías de concordancia en el SD: el rasgo de masa en asturiano". In: Antonio Fábregas, Elena Felíu, Josefa Martín \& José Pazó (eds.), Los límites de la morfología. Estudios ofrecidos a Soledad Varela Ortega, 91-104. Universidad Autónoma de Madrid: Servicio de Publicaciones de la Universidad Autónoma de Madrid.

Chierchia, Gennaro. 2010. "Mass nouns, vagueness and semantic variation". Synthese 174. 99-149.

Chomsky, Noam. 1995. The minimalist program. Cambridge, MA: The MIT Press.

Chomsky, Noam. 2001. "Derivation by Phase". In Ken Hale: A Life in Language, edited by Michael Kenstowicz, 154. Cambridge, MA: The MIT Press.

Chomsky, N. 2005. “Three Factors in Language Design”. Linguistic Inquiry, 36: 1-22

Chomsky, Noam. 2013. "Problems of projection". Lingua 130. 33-49.

Chierchia, Gennaro. 2010. Mass nouns, vagueness and semantic variation. Synthese 174. 99-149.

Cinque, Guglielmo. 2009. "The fundamental left-right asymmetry of natural languages". In Sergio Scalise, Elisabetta Magni and Antonietta Bisetto (eds.), Universals of language today, pp. 165-184. Dordrecht: Springer.

Costa, João and M. Cristina Figueiredo Silva. 2002. "Notes on nominal and verbal agreement in Portuguese". Rivista di Grammatica Generativa, 27: 17-29.

Déchaine, Rose-Marie, Raphaël Girard, Calisto Mudzingwa and Martina Wiltschko. 2014. "The internal syntax of Shona class prefixes". Language Sciences 43. 18-46.

Embick, David and Rolf Noyer. 2001. "Movement Operations after Syntax". Linguistic Inquiry 32: 555-595.

Fassi Fehri, Abdelkader. 2016. "Semantic gender diversity and its architecture in the grammar of Arabic". Brill's Journal of Afroasiatic Languages and Linguistics 8: 154-199.

Halle, Morris and Alec Marantz. 1993. "Distributed morphology and the pieces of inflection". In The view from Building 20, edited by Kenneth Hale and Samuel J. Keyser, 111-176. Cambridge, MA.: The MIT Press.

Higginbotham, James. 1985. "On Semantics". Linguistic Inquiry 16. 547-621.

Jones, Michael. 1993. Sardinian syntax. London: Routledge.

Kramer, Ruth. 2015. The Morphosyntax of gender. Oxford: Oxford University Press.

Lausberg, Heinrich. 1971. Linguistica romanza. II Morfologia. Milano: Feltrinelli.

Manzini, M. Rita and Leonardo M. Savoia. 2005. I dialetti italiani e romanci. Morfosintassi generativa, Alessandria: Edizioni dell'Orso,

Manzini, M. Rita and Leonardo M. Savoia. 2007. A Unification of Morphology and Syntax. Investigations into Romance and Albanian dialects. London: Routledge.

Manzini, M. Rita and Leonardo M. Savoia. 2011a. Grammatical Categories. Cambridge: Cambridge University Press.

Manzini, M. Rita and Leonardo M. Savoia. 2011b. Reducing 'case' to denotational primitives: Nominal inflections in Albanian. in Linguistic Variation 11, 76-120.

Manzini, M. Rita and Leonardo M. Savoia. 2017a. "N morphology and its interpretation: The neuter in Italian and Albanian varieties". In Anna Bloch-Rozmej and Anna Bondaruk (eds.), Constraints on Structure and Derivation in Syntax, Phonology and Morphology, pp. 213-236. Frankfurt: Peter Lang. 
Manzini, M. Rita and Leonardo M. Savoia. 2017b. "Gender, number and inflectional class in Romance". In Joseph Emonds and Markéta Janebova (eds.). Language Use and Linguistic Structure, pp. 263-282, Olomouc: Palacky University Olomouc.

Manzini M. Rita and Leonardo M. Savoia, forthcoming. "N morphology and its interpretation: Romance feminine/plural -a". In Silvio Cruschina (ed.), Proceedings of CIDSM 2016.

Manzini M. Rita, Benedetta Baldi and Leonardo M. Savoia, forthcoming. "Asymmetries in the positioning of plural morphology in DPs in $-s$ and $-i$ systems: A Romance comparative perspective". In Proceedings of CIDSM 2018.

Nevins, Andrew. 2011. "Multiple agree with clitics: person complementarity vs. omnivorous number". Natural Language and Linguistic Theory, 29: 939-971.

Marantz, Alec. 1997. "No escape from syntax: Don't try morphological analysis in the privacy of your own lexicon". University of Pennsylvania Working Papers in Linguistics 4. 201-25.

Meyer-Lübke W. 1899. Grammatik der Romanischen Sprachen. Dritter Band: Syntax. Leipzig

Molinu, Lucia. 2013. "Riflessioni sulle realizzazioni di /-s/ in alcune parlate sarde confrontate con quelle di alter varietà romanze", contribution presented at XXVIIe Congrès International de Linguistique et de Philologie Romanes, Nancy, 15 -20 Juillet 2013.

Oltra-Massuet, Isabel and Karlos Arregi, 2005. "Stress-by-Structure in Spanish". Linguistic Inquiry 36(1). 43-84.

Picallo, Carme. 2008. "Gender and number in Romance". Lingue e Linguaggio VII. 47-66.

Pomino, Natascha. 2012, "Partial or complete lack of plural agreement: The role of morphology". In Sacha Gaglia and Marc Olivier Hinzelin (eds.), Inflection and Word Formation in Romance Languages, pp. 201-230, Amsterdam: John Benjamins.

Roberts, Ian. 2010. Agreement and Head Movement. Cambridge, Mas.: The MIT Press.

Rohlfs, Gerhard. 1968 [1949]. Grammatica storica della lingua italiana e dei suoi dialetti. Morfologia. Torino: Einaudi.

Sanna, Antonio. 1975. Il dialetto di Sassari (e altri saggi). Cagliari, Edizioni 3T.

Sauzet, Patrick. 2012. "Occitan plurals. A case for a morpheme-based morphology". In Sacha Gaglia and Marc Olivier Hinzelin (eds.), Inflection and Word Formation in Romance Languages, pp. 179-200, Amsterdam: John Benjamins.

Savoia, Leonardo M. 2015. I dialetti italiani. Sistemi e processi fonologici nelle varietà di area italiana e romancia. Pisa, Pacini.

Savoia, Leonardo M., M. Rita Manzini, Ludovico Franco and Benedetta Baldi. 2017a. "Nominal Evaluative Suffixes in Italian". In Roberta D'Alessandro, Gabriele Iannàccaro, Diana Passino and Anna Maria Thornton (eds.), Di tutti i colori. Studi linguistici per Maria Grossmann, pp. 283-300. Utrecht: Utrecht University Press.

Savoia, Leonardo M., M. Rita Manzini, Benedetta Baldi and Ludovico Franco. 2017b. "A Morpho-syntactic Analysis of Evaluatives in Italian”. In Studi Italiani di Linguistica Teorica e Applicata, vol. XLVI. 413-440.

Vikner, Sten. 1997. "Vo-to-I' movement and inflection for person in all tenses". In The New Comparative Syntax, edited by Liliane Haegeman, 189-213. Edinbourgh: Longman Linguistics Library. 